\title{
Voces de resistencia al Conflicto Armado en Colombia: la experiencia del teatro como alternativa de comunicación y reconstrucción de lo público en el municipio de Tumaco ${ }^{3}$
}

\author{
Voices of resistance against the armed conflict: the experience of the theater as an alternative of \\ communication and reconstruction of what's public in the municipality of Tumaco \\ Vozes de resistência ao Conflito Armado na Colômbia: a experiência do teatro como alternativa de \\ comunicação e reconstrução do público no município de Tumaco
}

\section{Resumen}

El artículo se propone comprender la experiencia de Teatro por la Paz, un colectivo de jóvenes y mujeres del municipio de Tumaco-Nariño, quienes a través de sus narrativas y discursos promueven escenarios de resistencia y liberación frente a la violencia, la impunidad y el abandono estatal. Las categorías que se analizan son: el conflicto social y su relación con la movilización social desde las prácticas de comunicación alternativa, la ciudadanía desde la participación y la cooperación y la reconstrucción de lo público desde la apropiación del territorio y la capacidad de los agentes de crear escenarios de desarrollo humano y social en contextos de inequidad social.

Palabras clave: conflicto social, conflicto armado, comunicación, teatro, resistencia y reconstrucción de lo público.

Recibido: 31 de abril de 2016, evaluado: 9 de mayo de 2016, aprobado: 12 de mayo de 2016

1 Magíster en Política Social de la Pontificia Universidad Javeriana y Comunicadora Social y Periodista, de la Universidad Autónoma de Occidente, con experiencia en docencia universitaria. Correo electrónico: mariech30@gmail.com

2 Estudiante de Comunicación Social y Periodismo de la Corporación Universitaria Minuto de Dios. Integrante del Semillero de Investigación del proyecto Gestión del conflicto y reconstrucción de lo público en contextos de inequidad social: Análisis de la práctica de resistencia comunicativa de colectivos artísticos en el pacífico colombiano. Correo electrónico: nataliaev27@gmail.com

3 El presente artículo está sustentado en la investigación titulada Gestión del conflicto y reconstrucción de lo público en contextos de inequidad social: Análisis de las prácticas resistencia comunicativa de colectivos artísticos en el pacífico colombiano, financiada por la Corporación Universitaria Minuto de Dios a través de la IV Convocatoria para el desarrollo y fortalecimiento de la investigación en Uniminuto. En él participan los docentes Luz Marina Echeverría Reina, Yulieth Aldana Orozco, Andrea Forero Hurtado, Luis Carlos Rodríguez Páez y, como estudiante de Semillero de investigación, Natalia Díaz. 


\section{Abstract}

This article aims to comprehend the experience offered by Theater for Peace [Teatro por la Paz], a collective of young people and women from Tumaco-Nariño, who promote through their narratives scenarios of resistance and liberation against the violence, impunity and the abandonment by the state. The analyzed categories consist in: the social conflict and its relation with the social mobilization from the practices of alternative communication, the citizenship from the participation and the cooperation and the reconstruction of what's public from the appropriation of the territory and the capacity of the agents for creating scenarios of human and social development in a context of social inequity.

Keywords: social conflict, armed conflict, communication, theater, resistance, re construction of what's public.

\section{Resumo}

O artigo propõe-se compreender a experiência de Teatro pela Paz, um coletivo de jovens e mulheres do município de Tumaco-Nariño, quem através de suas narrativas e discursos promovem cenarios de resistência e libertação em frente à violência, a impunidade e o abandono estatal. As categorias que se analisam são: o conflito social e sua relação com a mobilização social desde as práticas de comunicação alternativa, a cidadania desde a participação e a cooperação e a reconstrução do público desde a apropriação do território e a capacidade dos agentes de criar cenarios de desenvolvimento humano e social em contextos de inequidad social.

Palavras-chave: conflito social, Conflito Armado, Comunicação, Teatro, Resistência e Reconstrução do público. 


\section{Contexto del Conflicto Armado en Tumaco}

Tumaco no sólo se ha caracterizado por ser cuna de grandes figuras de fútbol, en el ámbito político se le reconoce por ser el único municipio en la historia colombiana que desde el año 2001 al 2003 llegó a tener más de 16 alcaldes. Esta crisis política se le atribuye dado a que en el año 2001 fue elegido y posteriormente destituido el señor Samuel Alberto Escrucería Manzi, a pesar de estar inhabilitado por 10 años para ocupar cargos públicos por el delito de peculado contra la Caja Agraria en el año de 1992. Así lo relata el Periódico El Tiempo en el 2004.

De acuerdo con el informe de la Fundación Ideas para la Paz, denominado Dinámicas del conflicto Armado en Tumaco, en este territorio operan el frente Daniel Aldana y Mariscal Sucre de las Farc-ep. Por mucho tiempo estuvo el Bloque Libertadores del Sur - Autodefensas-, quienes en el año 2005 se desmovilizaron. Vale la pena anotar que, en el año 2006, con el propósito de recuperar el poder que mantuvieron los paramilitares surgieron nuevas bandas criminales con nombres como Las Águilas Negras y los Rastrojos que aún siguen delinquiendo en Tumaco (FIP,USAID y OIM, 2014).

De acuerdo con los datos del Observatorio del Delito de la Policía Nacional, del 2010 al 2015 en Tumaco se registraron 1.142 homicidios, 18 homicidios colectivos y más de 158 acciones de subversión en las que se incluyen atentados a instituciones, a infraestructura eléctrica, emboscadas y hostigamiento. El Sistema Único de Víctimas (RUV) sostiene que en el año 2015 se registraron en el municipio de Tumaco 2.924 víctimas desplazamientos, 306 amenazas a la población y 43 homicidios. Según las autoridades, estos hechos violentos están relacionados con el progresivo aumento de los cultivos de coca y los enfrentamientos entre los grupos armados por las rutas del narcotráfico en el puerto.
El periódico El País de Cali (2013) relata en un informe especial denominado ¿Por qué las FARC se ensañaron con Tumaco? Que en el año 2013 las Farc atacaron 17 torres de energía dejando a la población sin luz por 19 días, lo que generó que el presidente Juan Manuel Santos se desplazara a la región para hacer un consejo de seguridad. Se estima que el atentado provocó pérdidas por más de 20 mil millones de pesos — aproximadamente unos 6 millones de dólares-, además, de acuerdo con el periódico El Tiempo (2015), en junio de ese año las Farc atentaron contra el Oleoducto Transandino provocando el derrame de $410 \mathrm{mil}$ galones de petróleo sobre el mar, razón por la que se decretó a Tumaco en emergencia ambiental.

Actualmente, pese a contar con escuadrones de la fuerza pública en todo el territorio, las personas se sienten vulnerables frente a la violencia generada por los grupos al margen de la ley, y es justo en este panorama que adquieren importancia las iniciativas de comunicación que permiten a la comunidad promover formas de desarrollo humano y social.

\section{Teatro por la Paz}

Teatro por la paz es un grupo de mujeres y jóvenes que hacen teatro de resistencia a la violencia, al olvido estatal, a la impunidad y demás problemas que aquejan a los pobladores de la región de Tumaco. Se conformó en el año 2009 a través un convenio con el Servicio Civil para la Paz de Alemania - Ageh - y la Pastoral Social. Con el acuerdo firmado se hizo una convocatoria a través de los grupos juveniles y catequistas ${ }^{4} \mathrm{de}$ diferentes barrios; una vez llegaron los interesados, la Nicaragüense Norma Rivera Salazar emprendió el proyecto implementando la pedagogía del teatro del oprimido. Se crearon tres grupos de teatro: el grupo de mujeres Tumatai que significa en lengua de los Tumapaes $^{5}$ tierra de mujeres y hombres fuertes, el grupo Araña autodenominados tejedores de red, en el barrio Nuevo Milenio ${ }^{6}$ y el grupo

4 Personas que se encargan de instruir y educar en la fe cristiana.

5 Indígenas que habitaron la región de Tumaco.

6 Territorio de invasión de comunidades desplazadas de la violencia y con los altos índices de criminalidad. 
Cien Pies en el barrio La Florida, llamados así no por el animal - ciempiés - sino porque dicen ser cien pies que trabajan por la paz y la justicia.

Actualmente ya no cuentan con la cooperante de la Ageh, ahora los grupos se fusionaron y se asumen como un equipo que pretende: a) crear colectivamente una política de memoria y dignificación de las víctimas a través del teatro, b) construir un proyecto de vida para transformar las realidades permeadas por la inequidad, el abandono y la falta de oportunidades, c) reflexionar, debatir y construir espacios de participación y luego llevar a la comunidad un mensaje a través de las obras de teatro y d) constituirse como un espacio de comunicación, donde se comparten historias, preocupaciones y propuestas.

\section{Aproximación teórica del conflicto social}

El conflicto es un concepto que ha sido abordado de múltiples maneras de acuerdo con las diferentes disciplinas. Desde la Sociología, Pedro Luis Lorenzo Cadarso nos dice en su libro titulado Principales teorías sobre el conflicto social (2011) que ésta categoría está relacionada con los estudios del marxismo, el funcionalismo y los nuevos movimientos sociales. Sin duda, en cada apuesta teórica la definición de conflicto social cambia. Para el marxismo, el conflicto es inherente a todo sistema social y se considera un imperativo estructural mientras la sociedad esté conformada de forma clasista.

El conflicto o las tensiones generadas a partir de la lucha de clases se representan en dos esferas: el orden social, en el que convergen la actitud de las clases antagónicas y las relaciones de poder existentes como la clase dirigente - representada por los actores conservadores que se niegan a los cambios estructurales y que buscan la forma de perpetuarse como clase dominante- y la clase sometida que busca transformar su realidad. La otra esfera es la socioeconómica y aquí el conflicto es entendido como contradicciones a causa de los intereses de clases, es decir, las formas de generar riquezas versus el desarrollo de las fuerzas productivas.
Comprendiendo a Cadarso (2011), en el marxismo el conflicto social no es más que una relación antagónica de clases entre dominados y sometidos que puede variar a una clase ascendente que busca sustituir a la dominante. De otra parte, el funcionalismo fue una corriente que también propuso entender el conflicto social a partir de la forma como está constituida la sociedad, por instituciones que satisfacen las necesidades sociales. En ese orden de ideas, el conflicto social está determinado por las anomalías presentes en el funcionamiento de las instituciones.

Para Talcott Parson, máximo representante del funcionalismo, los conflictos no eran más que malentendidos en relaciones con los planes de acción de los actores sociales, o desviaciones con respecto al modelo normativo.

En la década de los 80 's del siglo pasado vino otra corriente sociológica interesada en los nuevos movimientos sociales, esas formas de acción colectiva que no eran originadas únicamente por una lucha de clases entre la clase dirigente y la clase dominada - como lo planteaba el marxismo-, sino por otras formas de injusticias y resignificadas por movimientos ambientalistas, estudiantiles, pacifistas, entre otros. Aquí nace otra forma de entender los conflictos a partir de la teoría conflictualismo liberal, que explica la categoría de grupos sociales, como formas de organización que interpelan diferentes signos de injusticias en la sociedad. Esta teoría tiene profunda relación con las formas de comprender las acciones colectivas desde un marco de interpretación que va desde las redes de solidaridad existentes en la acción hasta los rituales, los lazos de sociabilidad, identidad colectiva y demás.

A la luz de lo indagado, el colectivo de Teatro por la Paz acoge la categoría de grupo social, puesto que, al comprender esta iniciativa en términos de acción colectiva, se pueden distinguir elementos propios de las corrientes contemporáneas en la que se afirma que la acción no sólo es una respuesta a la injusticia, sino que también es un lugar de comunicación, de interacción permanente de subjetividades, de mundos posibles, de significados y 
tradiciones que ponen a los agentes en una lucha por transformar realidades.

Según la categoría de grupo social, el conflicto social es interpretado como series de hechos injustos que son interpelados por los grupos sociales desde sus estructuras cognitivas, sus tradiciones, sus discursos políticos y sus ideas previas y posteriores a la dinámica de grupo. Lorenzo Cadarso lo define como "proceso de interacción contenciosa entre actores sociales que comparten orientaciones cognitivas, movilizados por diversos grados de organización y que actúan colectivamente, de acuerdo con expectativas de mejora, de defensa de la situación preexistentes o proponiendo un contraproyecto social" (2011, p. 12).

\section{Voces de resistencia al Conflicto Armado: Comunicación en la acción colectiva}

La resistencia ha sido un concepto que ha sido estudiado desde los tiempos del marxismo y tiene mucho que ver con los conflictos sociales antes abordados. Son múltiples los repertorios de protesta de las acciones colectivas y los diferentes movimientos sociales que buscan resistirse a las formas de dominación, muchas de ellas no han tenido más recurso que emplear la violencia para ser escuchados y otras acciones se han caracterizado por constituir una lucha simbólica. Se puede concluir que los estudios de las acciones colectivas no se encargan de evaluar el carácter moralista de los repertorios de acción sino de comprender, a la luz de la gestión, cómo mantienen los propósitos firmes, cómo se comunican, cómo se van organizando y creando identidades colectivas y cómo se gestiona el conflicto social e incluso los conflictos propios de la organización.

Las raíces de la resistencia están ligadas a las estructuras de poder que se gestan en la sociedad y que se han materializado en formas de dominación. Se puede interpretar que la resistencia es una práctica de comunicación de las comunidades para interpelar ciertos dispositivos de poder que están vulnerando sus derechos. De acuerdo con Michael
Foucault (1994), la resistencia guarda una estrecha relación con el poder, es la fuerza que permite a los ciudadanos modificar su status quo. De otra parte, Bobbio (1985) nos señala que las esferas públicas se caracterizan por las relaciones de poder y de obediencia y es el espacio público, el espacio de lo político, donde las sociedades reconfiguran las nociones de libertad:

El Estado, y cualquier otra sociedad organizada donde hay una esfera pública, no importante si es total o parcial está caracterizado por relaciones de subordinación entre gobernantes y gobernados, esto es, entre detentadores del poder de mandar y destinatarios del deber de obedecer, que son relaciones entre desiguales (Bobbio, 1985, p. 15).

Bobbio (1985) nos sumerge en un campo donde es inevitable reconocer las relaciones de poder y las relaciones de subordinación. Las luchas sociales son el resultado de una sociedad que asume la opresión como formas desiguales de convivir y gobernar, por eso este fenómeno se hace más interesante en la medida que las sociedades deciden transformar estos niveles de subordinación, a niveles políticos y transformadores.

Las afirmaciones anteriores nos remiten a un concepto clave en los procesos de lucha reivindicativa, a saber, procesos de resistencia civil. Es decir, formas de asumir el deber ciudadano y dirigir la lucha a través de acciones no violentas, de carácter cívico e innovador. Las sociedades son las que determinan los niveles de innovación en la lucha reivindicativa, no existe un manual que determine cómo deben estudiarse las acciones colectivas, por ello es fácil encontrarse distintas teorías de las mismas, sobre las diferentes formas de actuar y sentir la acción. Por tanto, los procesos de resistencia derivan en cómo las agentes asumen el contexto, cómo los procesan y como lo materializan. Para el caso de Teatro por la Paz, la lucha y la resistencia es civil no violenta.

Michael Randle (1998), nos habla de la resistencia civil como un método organizado y no violento. $\mathrm{Al}$ respecto señala: 
La resistencia civil es un método de lucha política no violenta basada en la idea básica de que los gobiernos dependen en último término de la colaboración, o por lo menos de la obediencia de la mayoría de la población, y de la lealtad de los militares, la policía y de los servicios de seguridad civil. O sea que está basada en las circunstancias reales de poder político. Funciona a base de movilizar a la población civil para que retire el consenso de procurar socavar las fuentes de poder del oponente y de hacerse con el apoyo de terceras partes. Sus métodos abarcan desde la protesta y la persuasión hasta la no cooperación social, económica y política y por último hasta la intervención no violenta (Randle, 1998, p. 25).

Ahora bien, teniendo en cuenta lo anterior vale la pena preguntarse ¿cómo comprende y cómo se resiste al conflicto armado el grupo de Teatro por la Paz? Para ello, es importante hacer énfasis primero en el panorama general que le permite al grupo social la necesidad de agruparse.

Tumaco está situado en un lugar estratégico para que grupos armados y bandas criminales se disputen el territorio para fines de narcotráfico. El Estado, en defensa de la soberanía, también se suma a este control dejando a la población civil suspendida en un péndulo que atraviesa a estos actores.

A este panorama, los estudios de política y sociología en nuestro país lo han denominado conflicto armado y no está lejos de lo que se plantea en los estudios del conflicto social y sobre resistencia, que indican básicamente una relación de poder y dominación. Se puede decir que este conflicto tiene cuatro aristas importantes de comprender: a) la guerrillera, b) la paramilitar, c) la del narcotráfico y d) la estatal. La identificación de estas categorías permite inferir que en este conflicto armado subyacen diferentes tipos de relaciones antagónicas que dan como resultado la guerra. El conflicto armado, además de ser una categoría de análisis, es una categoría jurídica al ser acogida por el Estado colombiano en el marco del Derecho Internacional Humanitario y que otorga un estatus de beligerancia a los actores en confrontación.
La guerrilla en Colombia, como es de conocimiento, se origina por una dominación de la clase política dirigente hacia una población campesina. Esta dominación termina generando tensiones tan fuertes que los campesinos en cabeza de Pedro Antonio Marín Rodríguez, alias "Manuel Marulanda" asumen el liderazgo de las Autodefensas Campesinas Liberales en las décadas de los 50's, del siglo pasado, y posteriormente de las Farc (Fuerzas Armadas Revolucionarias de Colombia); esto con el fin de enfrentar el conflicto a través de las armas y otras vías de hecho.

Cadarso (2011) es claro en afirmar que las revoluciones entendidas como movimientos de gran espectro social, y con unos planteamientos ideológicos encaminados a un contraproyecto social son entendidas en las nuevas teorías del conflicto como principales formas de conflicto social y que sin duda evidencia una confrontación de intereses socioeconómicos.

Por otra parte, los paramilitares - grupos de autodefensa - se originan en Colombia en la década de los 70 's, del siglo pasado, y también guardan un vínculo de antagonismo principalmente con las guerrillas. Su propósito fue en un principio conformar alianzas para combatir a la guerrilla y su lucha marxista leninista que por esta época crecía exponencialmente. El Narcotráfico, por su lado, ha sido un fenómeno que en la época de los 80 's sometió a la población colombiana a una guerra que no se podía controlar; bombas, masacres y atentados fueron las vías que los diferentes carteles utilizaron para enfrentar la relación de antagonismo con el Estado colombiano por el tema de la extradición y otros pactos con Estados Unidos para la lucha en contra este flagelo.

Finalmente, el Estado ha mantenido una lucha por la soberanía del país, movilizando tropas en lugares donde tienen presencia estos grupos e invirtiendo recursos provenientes de Estados Unidos en el denominado Plan Colombia ${ }^{7}$ y así combatir el narcotráfico y la guerra con estos grupos. De acuerdo con la Revista Semana (2014), Colombia en la última década ha invertido 230 billones de 
pesos colombianos, aproximadamente unos 100 mil millones de dólares.

Frente a este contexto histórico vale la pena comprender cómo se resisten a ese conflicto armado el grupo de Teatro por la Paz. A través de la metodología de grupo nominal y el foro de discusión, la comunidad expresó e identificó el Conflicto Armado como el conflicto social por el cual ellos le dan sentido a la acción colectiva. Lo definen como "un conjunto de acciones bélicas que vulneran los derechos de la población y atentan contra cultura y la dignidad humana" (Teatro por la Paz, 2015, Taller de grupo Nominal). Asimismo, identificaron, según lo que han vivido y su percepción del contexto, varias injusticias provocadas por ese conflicto como: a) violencia - homicidios y asesinatos colectivos, desplazamiento, amenazas, atentados a instituciones y espacios públicos-, b) falta de conciencia y sentido propio de la población que ha naturalizado la violencia, c) paternalismo - la gente no quiere luchar, asume el rol de víctima-, d) daño al medio ambiente y e) reclutamiento de menores - por parte de todos los grupos como el ejército, guerrilla y paramilitares-.

A continuación algunas formas de vivir y comprender el conflicto armado del grupo de Teatro por la Paz:

Uno de los problemas que hemos discutido como grupo, es el reclutamiento de jóvenes. A nuestro compañero Leonardo, el Ejército casi se lo lleva, justo cuando nos disponíamos a viajar a Cali para un Encuentro Ecuménico, el Ejército lo retuvo como cinco horas, porque él no había definido su situación militar, sabemos que es una obligación en Colombia, pero Leonardo está estudiando, se supone que no tenían que hacer eso, y gracias a los contactos que tenemos con Derechos Humanos, no se lo llevaron, pero y ¿̇los demás?, esta injusticia ha sido un motivo más para debatirla y evidenciarlo en nuestras obras (Mary Cruz Cruel, 2015, Taller de grupo Nominal).
El grupo comprende el Conflicto Armado a través del diálogo que pone en evidencia sus percepciones sobre la impunidad, la injusticia y el atropello a los derechos humanos desde sus experiencias personales. A estas prácticas, las teorías contemporáneas sobre la acción colectiva y los conflictos sociales, como las de David Snow, et al. (1986) y Alberto Melucci (citado por Enrique Laraña 1994) lo denominan procesos enmarcadores. A través de ellos se amplía el espectro de las lógicas de conformación y organización, su punto de inflexión es comprender las particularidades de los sujetos, desde las identidades colectivas, desde la construcción de mundos posibles que diversifican la acción y la eleva a otras categorías como sobrevivir juntos y compartir historias juntos. Esto nos permite entender por qué las miradas heterogéneas en el grupo enriquecen la reflexión. Por ejemplo, las mujeres por su parte ven con mayor preocupación la descomposición familiar, el dolor de una madre ante la pérdida de su hijo sin que haya la más mínima reparación, en cambio, los jóvenes ven con mayor indignación cómo son presa fácil para el reclutamiento forzado.

David Snow, (1992, como se citó en Chihu, 2006) plantean cuatro dimensiones de comprender los marcos de acción colectiva en la organización y los denomina como esfuerzos consientes para compartir subjetividades y formas de comprender el mundo, importantes en la legitimación y movilización de la acción colectiva. El primero de ellos es el puente entre marcos, que distingue a los medios y canales de comunicación para promover la movilización; el segundo es la ampliación de los marcos, que hace referencia a las conductas individuales que se comparten en la acción y los valores que se construyen de manera colectiva; el tercero es la extensión de los marcos, que intenta comprender las metas que se proponen y la transformación paulatina de la ideología que identifica la acción; por último, la transformación de los marcos, que es la permanente comunicación que implica la construcción de nuevos sentidos y valores de la acción.

7 El Plan Colombia es un acuerdo bilateral firmado por los gobiernos de Colombia y Estados Unidos en el año de 1999. Y su objetivo principal acabar con el conflicto armado y el narcotráfico a través de una estrategia militar. 
De esta manera se puede comprender que, en el universo de pensamientos y vivencias de los agentes del Teatro por la Paz, otros conflictos como la descomposición familiar y la corrupción política se convierten en oportunidades para repensar las formas de lucha de la organización social. Así adquieren sentido las palabras de John Dewey cuando menciona: "El conflicto es el tábano del pensamiento, estimula nuestra percepción y nuestra memoria. Fomenta la investigación, sacude nuestra pasividad de ovejas" (Dewey, 1966, p. 300).

A continuación se evidencia el testimonio de una de las integrantes que permite comprender la relación expuesta en el párrafo anterior.

Nosotros basamos nuestra lucha desde la dignidad humana y el respeto a la vida. Tenemos la necesidad de hablar y reflexionar sobre tantos casos que ocurren en Tumaco y sus zonas rurales, todos los casos son reales, ninguno es inventado, es una forma de honrar a cada víctima, pero también de decirle al pueblo que no se quede callado ni se acostumbre a la ver la violencia de manera natural. Antes éramos un grupo motivados por hacer teatro, pero luego de estar juntos, contarnos nuestros problemas, angustias y nuestros casos de violencia queremos seguir con este objetivo, de sanación de estos hechos que nos han marcado y han marcado a la sociedad (Mary Cruz Cruel, 2015, Taller de socialización realizado por el equipo de investigación, Tumaco).

La apuesta alternativa que hace el proyecto de Teatro por la Paz, a partir del conflicto armado en Tumaco, es fomentar la capacidad de soñar. Los jóvenes, por ejemplo, han descubierto el sentido de la superación y liberación ciudadana a través de la educación. Ellos aseguran que es otra forma de enfrentar estos flagelos con otras armas. Cuando se instruye el sentido de la vida cambia, los fenómenos adquieren otra perspectiva. Muchos de los jóvenes están estudiando en universidades licenciaturas afines con las humanidades y las ciencias sociales para comprender mucho más el contexto y contribuir con la comunidad.
Para muchos de nosotros, el teatro nos ha permitido entender que la vida va mucho más allá de lo que nos ofrece la región, ahora somos jóvenes que luchamos por nuestro sueño, aun conociendo que nos enfrentamos a un contexto de violencia. El teatro nos ha permitido recuperar esa capacidad de indignarnos por los hechos atroces que pasan en nuestra región. Somos jóvenes que hemos podido transformar nuestro rumbo, nuestra vida y ahora podemos encontrar nuevas formas de apostarle al desarrollo social de nuestro territorio (Johana Quiñones, 2015, Entrevistada por equipo de investigación, Tumaco).

Es justo reconocer que la comunicación toma un papel relevante en las formas de entender el conflicto y gestionarlo. Las formas en las que se consolidan las acciones colectivas necesariamente pasan por un proceso de comunicación entre los agentes, por eso en este artículo se pretende comprender el conflicto social - relaciones antagónicas producidas en el entorno- como los objetivos principales por los que la acción colectiva asume su lucha y va abriendo caminos a nuevos repertorios de protesta y formas de acción social que van transformando las injusticias en oportunidades para comprender el entorno y enfrentarlas desde otras alternativas encaminadas al desarrollo humano y social. Se entiende el conflicto desde las lógicas de la acción colectiva, como una oportunidad en función del cambio social. Así lo advierte Silva (2008) en su artículo denominado teoría del conflicto, un marco teórico necesario. Allí indica:

La simple dinámica del conflicto social tiene la propiedad de gestar cambios sociales, pues los partícipes del conflicto, obligados por las circunstancias dadas por la lucha, deben diseñar nuevos medios, elaborar proyectos originales que sirven al propósito inmediato del conflicto, pero cuyos beneficios sociales se prolongan en la historia mucho más allá del conflicto o repercuten sobre áreas nunca imaginadas (p. 39).

A partir de esto es posible afirmar que los procesos de comunicación e interacción del grupo de 
Teatro por la Paz, en la reflexión sobre la violencia y en la posterior estructuración de un discurso que busca reivindicar los derechos y la dignidad humana, es un proceso de resistencia civil no violenta que conduce a una alternativa distinta de mirar la guerra y proponer posibles soluciones para la construcción de un tejido y un desarrollo humano y social; es decir, busca una resignificación de lo público.

Somos un grupo consiente que no queremos hacer otro tipo de teatro distinto a la denuncia. Ese es nuestro sello, nosotros hemos transformado nuestro entorno gracias al teatro, hemos asumido nuestro deber como ciudadanos. Y nuestro compromiso es seguir haciendo memoria, seguir trabajando por la paz, promover esos principios democráticos (Mary Cruz Cruel, 2015, entrevista individual realizada por el equipo de investigación).

Las comunicaciones gestadas en el colectivo de Teatro por la Paz, para afrontar el conflicto armado, se enmarcan en lo que plantea el investigador César Rocha, quien define la comunicación como "procesos de interacción, de recíproca acción entre varios agentes que producen conocimiento y transformación de las realidades fenomenológicas" (Rocha et ál., 2013, p. 45). A partir del conflicto armado se producen diversas significaciones y sentidos que los sujetos construyen alrededor del entorno social.

En el grupo de Teatro por la Paz, las manifestaciones artísticas se constituyen en una acción comunicativa que representa la construcción de sentidos en torno a problemas y dilemas que viven los actores sociales y que van reenfocando su lucha civil. Los repertorios de protesta y resistencia del grupo de Teatro por la Paz pasan por una comunicación intersubjetiva. Allí se promueven espacios de interacción como la lluvia de ideas sobre la violencia, sobre la memoria, las tradiciones culturales y debates como método de argumentación en la construcción de las obras; finalmente, se crean espacios de catarsis para expresar los problemas que enfrentan cada uno y que están relacionados con historias de pobreza, de desplazamiento, asesinatos y extorsiones. Estas prácticas comunicativas es el inicio para construir una cultura y apuesta política en las obras de teatro.

En nuestras obras tratamos de representar todos los contextos en los que la violencia ha permeado, por ejemplo, los hogares, las escuelas, y los barrios, los representamos incluso con metáforas, por ejem-plo, la madre simboliza la familia, la educación la libertad, la madre tierra nuestro territorio y así vamos adecuando todos los problemas a estos per-sonajes que al final tienen un mensaje propositivo de cambio (Johana Quiñones, 2015. Entrevistada por el equipo de investigación, Tumaco).

A partir de esto se puede reconocer lo que plantea Oscar Useche (2013), quien expresa que en el mundo contemporáneo los grupos sociales han venido configurando formas novedosas y creativas de constituirse y de permanecer juntos en la lucha política, éstas permiten a los agentes reenfocar la acción pública y darle un sentido alternativo a lo político.

En la revista el grupo de Teatro por la Paz publicó en el año 2015, con ayuda del Servicio Civil para la Paz de Alemania, se describe cómo es el proceso de comunicación y participación colectiva para la construcción de una obra. Se puede percibir los alineamientos o dimensiones que plantea $\mathrm{Da}$ vid Snow (1992, citado por Aquiles Chihu 2006). La movilización recoge todo un ritual de comunicación, discusión y proyección política de los ciudadanos.

Desarrollamos un proceso de formación integral y continua de los integrantes a través de talleres semanales, presentaciones, encuentros, intercambio de experiencias con otras iniciativas artísticas, y culturales a nivel local, regional y nacional. Cada año hacemos un montaje de una obra diferente que se estrena en septiembre en el marco de la Semana por la Paz, posteriormente, se difunde en diferentes escenarios y regiones. La construcción colectiva del montaje, así como la investigación de los fundamentos teóricos, culturales y tradicionales del pacífico nariñense son los pilares del proceso de creación. Después de las presentaciones teatrales, se promueven conversaciones con el público para 
retroalimentar y facilitar el compartir experiencias similares, o para intercambiar metodologías de trabajo por medio de encuentros, foros y diplomados (Teatro por la Paz, 2015, p. 6).

Desde las dimensiones de los marcos de la acción colectiva se debe anotar que los agentes han librado unas luchas de reivindicación individual y colectiva y han transformado sus entornos en escenarios de participación política, de sociabilidad y seguridad. Construyen los espacios políticos y públicos a partir del conflicto, construyen sus identidades desde una lucha no violenta y construyen imaginarios y representaciones sociales que terminan en procesos de emancipación en un territorio determinado.

La comunicación nos permite comprender qué hacen los sujetos para asumir el conflicto y gestionarlo. Gestionarlo significa comprenderlo, problematizarlo, promover escenarios para la expresión $\mathrm{y}$, conjuntamente, buscar salidas emergentes o de mediano y largo plazo que garanticen la convivencia del grupo social o su desintegración por las vías diplomáticas y de respeto mutuo.

Las formas de comunicación del grupo de Teatro por la paz se podrían comprender desde lo que plantea Rosa María Alfaro (1993), quien define la comunicación como un acto natural a la vida humana y que no debe ser vista en función de los medios de comunicación sino como prácticas sociales de acción e interrelación de los sujetos:

Lo comunicativo es para nosotros una dimensión básica de la vida de las relaciones humanas y socioculturales. Es el reconocimiento de la existencia de actores que se relacionan entre sí dinámicamente, a través de medios o no, donde existe un UNO y otro, o varios OTROS, con quienes cada sujeto individual o colectivo establece interacciones objetivas y principalmente subjetivas (Alfaro, 1993, p. 27).

Lo interesante de los estudios sobre las nuevas formas de acción colectiva es que hacen posible comprender que la resistencia no sólo es propia de los grupos ampliamente reconocidos como los partidos de trabajadores, grupos guerrilleros o ambientalistas, sino también de otras formas de agrupación que al compartir a través de la comunicación sus visiones del mundo crean un entramado de significados alrededor de lo que es injusto. La injusticia, entonces, se convierte en el agente movilizador de la resistencia, construida desde la comunicación y que da lugar al acontecimiento. Useche (2012) lo define de la siguiente manera:

En la teoría de la resistencia, el acontecimiento se convierte en un concepto fundacional por cuanto define el sentido de lo que debe ser comprendido y de lo que es anhelado, deseado por los resistentes. Muchas veces aproximarse a lo inconmensurable de las acciones que rompen la tranquila reproducción de las estructuras dominantes, solo adquiere proporción si se acepta como un renacer, como un parto social, como una nueva vía a la que se ha ingresado por la vía del acontecimiento. El acontecimiento produce el protagonismo de cada uno de los resistentes, es su despliegue de su deseo de participar directamente, de hacer parte de la creación de novedades en cuyo transito hay que hacerse actor y no dejarse reducir el papel de representado (2012, p. 107).

El acontecimiento es una forma de comprender esos procesos de lucha reivindicativa del grupo de Teatro por la Paz. Cada uno de los resistentes del colectivo tiene un papel fundamental en la construcción de una lucha política a través del arte. El mismo colectivo se convierte en un motor de resistencia hacia esas mismas formas de dominación que impone el sistema y que ha hecho que los habitantes naturalicen un estado de pobreza. Por ello, la resistencia también se vuelve introspectiva, donde se recupera el derecho a soñar, a superarse, a convertirse en ciudadanos activos generadores de su propio desarrollo. A continuación una síntesis de cómo la actitud se convierte en una forma de resistencia.

Con el grupo de Teatro por la Paz, yo aprendí que uno tiene derecho a soñar, a luchar por nuestros sueños, a no confiarnos con lo que el sistema social y político nos da sino avanzar. Nuestra forma de resistir está también en la forma como 
nosotros somos conscientes que podemos cambiar (Lina Peña, 2015. Entrevistada por el Equipo de investigación, Tumaco).

Las narrativas son prácticas de comunicación, de creación de sentidos, de formas de comprender el mundo que los rodea, las narrativas pasan por un proceso de resignificación de lo cotidiano y de sanación de los hechos violentos que han marcado a los agentes colectivos. Las narrativas son el discurso que les permite a jóvenes y mujeres comprender su lugar como ciudadanos desde la mirada de personajes que denuncian, que fueron silenciados, asesinados por confrontar al sistema político.

A menudo, las narrativas incluyen el reconocimiento de otras obras literarias, que aportan un valor significativo en el objetivo que los agentes se proponen representar. Por ejemplo, el libro de Mario Benedetti El olvido está lleno de memoria y su poema Ese gran simulacro fue de inspiración para el grupo de Teatro por la Paz.

El olvido está lleno de memoria. Los desaparecidos, los enterrados en fosas clandestinas, aquellos que ni la muerte podrá su voz callar; aquellos que como tú vivían en el silencio, aprenderán a calentarse el corazón con los recuerdos. [...] El día o la noche en que el olvido estalle, salte en pedazos o crepite, los recuerdos atroces o los de maravilla quebrarán con sus gritos el dolor y el miedo a la noche y arrastrarán por fin la verdad por el mundo y esa verdad será que no hay olvido (Teatro por la Paz, 2014. Fragmento de la obra: El olvido está lleno de memoria).

Las metáforas y la reencarnación de las voces de las víctimas juegan un papel primordial en la constitución de las obras de teatro. Es una forma de reconstruir los hechos de una manera objetiva, también de recrear las realidades desde otras ópticas, de trascender al ámbito de lo público todas las formas de rechazo, indignación y las historias de las víctimas que han tenido que callar frente a las prácticas de dominación de los grupos al margen de la ley. A continuación un fragmento de la obra Mi otro yo, que sitúa a las víctimas en el papel de denunciantes y cuentan su historia antes y después de ser silenciadas.

Yo: soy una mujer de 24 años de edad y madre de tres niños a quienes quiero más que mi vida.

El otro yo: Un día como cualquier otro, estaba saliendo de la casa de una amiga cuando un hombre se bajó de una moto y me disparó. ¿Quiénes, y cuánto pagarían por mi muerte? ¿Cuánto vale el futuro de mis hijos sin su madre? [...] Fue tan repentino que la gente alrededor se quedó paralizada. El terror paraliza, te hace temblar [...] Fui asesinada el 3 de abril del 2009. ¡Un caso más! No he tenido juicio, ni abogado, ni sentencia, sigo esperando justicia, $¡$ mi caso sigue en la impunidad! (Teatro por la Paz, 2011. Fragmento obra: Mi otro yo).

Los montajes teatrales son prácticas estéticas que recrean el universo cultural de la cultura afrodescendiente y que se aprovechan para darle identidad a la resistencia. Las narrativas de las obras buscan reencontrarse con expresiones como los alabaos o los arrullos que son cantos de adoración a los santos y a los niños difuntos; generalmente van acompañados de instrumentos autóctonos como la marimba, el cununo y el guasá. Un ejemplo de ello es la incorporación del Chigualo ${ }^{8}$ en la obra El olvido está lleno de memoria, el cual adquiere un nuevo significado, pues, todas las víctimas comparten una historia común, son inocentes de una guerra, por tanto, todas merecen una despedida digna, a través de cantos y poemas, así como se les hace a los niños difuntos. Es una forma de hacer memoria de los hechos violentos.

Arrullo incorporado en la obra El olvido está lleno de memoria:

Buen viaje, buen viaje. El que viene y se va, buen viaje, buen viaje, Tu padrino y tu madrina te darán, buen viaje, buen viaje. Que la muerte te llevó, buen

8 El chigualo es una tradición propia del pacífico, que simboliza la despedida de un niño(a) que acaba de morir y a quien se le hace un homenaje por ser un alma inocente, el ritual incluye arrullos y ahí las cantadoras son las guían el viaje del niño. 
viaje, Buen Viaje, El que se embarca y se va, buen viaje, buen viaje, Que tus padres te dan, buen viaje, buen viaje, Tus hermanos quedaran, buen viaje, buen viaje, Y que el cielo te reciba, buen viaje, buen viaje, $Y$ que el cielo te reciba, buen viaje (Teatro por la Paz, 2014. Fragmento de la obra: el olvido está lleno de memoria).

Alabao incorporado en la obra Renacer:

¡Oiga María, oiga José! (bis)

En lo que hacemos pongamos fe (bis)

Vamos a la misa la eucaristía

iJesús lo hacia!

Esto es damagua y cabecinegro,

$\mathrm{Pa}^{\prime}$ artesanias de nuestro pueblo

Frutas sabrosas es lo que ofrezco,

De las cosechas de nuestro suelo.

Con río sano, con atarraya

Nuestro pescado nunca nos falla.

(Fragmento de la obra Renacer)

Finalmente, es importante resaltar que el teatro es un escenario de interacción de lo estético y lo político, dota de herramientas metafóricas, gestuales, visuales y sonoras para construir una comunicación con el universo del espectador. Se debe anotar, además, que el público lo conforman niños y adultos y el perfil es de múltiples referencias. Así pues, es necesario llegar a todos con un lenguaje que además de representar los hechos violentos, lleve al interlocutor a cuestionarse sobre los temas expuestos. Ranciere (2005) nos habla del arte como la redisposición de los objetos y las imágenes para transformar algo ya dado o modificar las miradas y percepciones del entorno colectivo. En el caso de Teatro por la Paz, las representaciones desde lo metafórico y lo lírico suscitan espacios para confrontar, transmitir sensibilidades a los individuos, confrontarlos y provocar sociabilidades.

\section{Reconstruir lo público desde la comunicación: prácticas de apropiación del territorio}

Los procesos de resistencia civil, analizados en el colectivo de Teatro por la Paz, nos llevan a comprender unas de las discusiones que la filosofía política se ha encargado históricamente de hacer, a saber, poner en la palestra académica los conceptos de lo público y lo privado y su irrefutable relación. Las diferentes organizaciones y colectivos han basado su lucha creando espacios para la reivindicación política que permite concebir un proyecto en defensa del bien colectivo, en el caso de Teatro por la Paz, todas las manifestaciones de repudio, de dolor, de injusticia, se han hecho desde el ámbito de lo público, es decir, de los espacios comunes a todos y de las virtudes públicas.

Para entender el concepto de lo público se remitirá a los postulados de Hanna Arendt (1994) quien, en su libro La condición humana, nos habla sobre la vida activa del hombre en sociedad, es decir, desde el ámbito político y social propios de la condición humana da una mirada a la supervivencia y permanencia del mismo y desarrolla un análisis de aspectos como la acción, el trabajo y la labor como aspectos que lo condicionan.

Solo la existencia de una esfera pública y la consiguiente transformación del mundo en una comunidad de cosas que agrupa y relaciona los hombres entre sí depende por entero de la permanencia. Si el mundo ha de incluir un espacio público no se puede establecerlo para una generación y planearlo solo para los vivos, sino que debe superar el tiempo vital de los hombres mortales (Arendt, 1993, p. 64).

En esta perspectiva, la esfera pública que ha construido el grupo de Teatro por la Paz es un proceso de permanencia, de producción de significados alrededor de los valores plurales que debe regir a una sociedad que en el caso de Tumaco ha sido permeada por la violencia. Los sujetos que ejercen 
procesos de ciudadanía activa, en cualquiera de sus formas, resignifican lo público, se convierten en críticos de las instituciones y reconstruyen nuevas formas de sociabilidad y confrontación del mundo que los habita.

Estas formas de reconstruir lo público no son posibles sin las dinámicas comunicativas al interior de la organización y que están relacionadas con el conflicto no sólo social - por el que se constituye la acción y que tienen que ver con contextos de vulnerabilidad, abandono, pobreza e inequidad social-, sino interpersonal —en donde se ponen en juego las relaciones de poder, las dificultades individuales y colectivas para afrontar los problemas, los retos y desafíos de la organización-.

Hanna Arendt (1993) menciona lo público como "el propio mundo y que es común a todos nosotros y diferenciado de nuestro lugar poseído privadamente en él" (p. 61). Este espacio es construido por las manos del hombre, en él cada uno de los sujetos construye significados y sentidos de acuerdo con el mundo que lo rodea, este espacio es plural y de permanente interacción.

La esfera pública, al igual que el mundo en común, nos junta y no obstante impide que caigamos uno sobre otro, por decirlo así, lo que hace tan difícil de soportar a la sociedad de masas es el número de personas, o al menos no de manera fundamental, sino el hecho de que entre ellas el mundo ha perdido su poder para agruparlas, relacionarlas y separarlas (Arendt, 1993, p. 62).

Lo público representa entonces la apropiación de un territorio que ha sido testigo de las imposiciones de los grupos al margen de la ley. A continuación, algunas ideas discutidas:

Lo público es para nosotros hacer uso de los espacios que tenemos como comunidad, las calles, los colegios y los parques, estos son espacios que son de todos y ahí convocamos a la comunidad. [...]
Lo público es el derecho a soñar, cuando se sueña, se logran objetivos y todos los jóvenes queremos se profesionales, para luego contribuir con nuestra sociedad. [...] Lo público es recuperar nuestras tradiciones culturales, nuestras manifestaciones artísticas. Por ejemplo, reconocer el chigualo como parte fundamental de nuestra cultura y que ahora se ha perdido. [...] Recuperar nuestras formas de comunicarnos con nuestros hijos, transmitir el conocimiento de generación en generación. Recuperar tradiciones como los alabaos, los arrullos?.

Lo anterior nos sitúa en el plano de la reconstrucción de lo público en un contexto como Tumaco, donde la institucionalidad ha perdido legitimación, donde las amenazas han logrado que las personas se refugien en sus casas o en las relaciones familiares que hacen parte de la esfera privada. Lo público, en escenarios de violencia y opresión se reconstruye desde las ciudadanías activas ${ }^{10}$, es decir, desde la identificación de los espacios públicos para el diálogo, la sociabilidad, la convocatoria, la recuperación de las relaciones humanas y la resistencia.

Cuando un ciudadano siente indignación moral, frente a los hechos que oprimen a la población, la movilización social es una valiosa alternativa de participación ciudadana. El grupo de Teatro por la paz asume que la resistencia no es sólo frente a los actores del conflicto armado, sino frente a una sociedad que naturaliza, que olvida y que calla. A continuación un fragmento de la obra Renacer, en el que se hace una crítica a esa sociedad impávida:

En la esquina alguien agoniza en medio de un gran charco de sangre. A su alrededor, un vecindario de culpables, tratan en vano conciliar el sueño. [...] ¡Diario matan a otro joven en este pueblo! Esto se está volviendo tan común, que la gente ahora saluda preguntando ¿a quién mataron hoy? o, ¿qué milagro que no se haya oído hablar de muerto hoy? [...] ¡Vean niñas esto si es que duro! Hace un año ya que desaparecieron a nuestros familiares, y la vecina sigue en este estado. ¡Un año sin hablar nada! ¡Qué

9 Voces de los participantes en Taller de lluvia de ideas, 2015, realizado por el equipo de investigación, Tumaco.

10 Boaventura de Sousa Santos (2006) define las ciudadanías activas de alta intensidad. Es decir, ciudadanía pluralista, activa en los procesos de transformación que trasciende las esferas no estatales. 
barbaridad! ¡Se dan cuenta que el silencio y el olvido son como una doble muerte! (Teatro por la Paz, 2011. Fragmento de la obra Renacer).

Ahora bien, para comprender el concepto de esfera pública en un contexto como Tumaco, nos remitiremos a Jürgen Habermas (1992) quien plantea que la esfera pública es una construcción que deviene de las relaciones mercantiles, de ahí que el autor proponga la categoría de la esfera pública burguesa, pues, en ella las personas se reúnen en público, se generan espacios para socialización y se construye la opinión pública. Habermas es enfático en abordar dos tipos de opinión pública: de instancia crítica y de notoriedad pública, referida al poder político y social. Además, la instancia receptiva de notoriedad representativa, la que es manipulativamente divulgada.

Habermas (1992) nos pone en un panorama en el que la publicidad y el mercantilismo han permeado las formas de concebir críticamente un sistema político. El capitalismo y la sociedad de consumo han generado unas dinámicas de opinión pública manipulada por los medios de comunicación. Lo anterior lleva a pensar que, en una región como Tumaco, donde el narcotráfico ha generado públicamente en la sociedad formas de concebir estilos de vida, se crea a su vez una esfera pública en la que importa producir dinero para lograr salir de la pobreza y legitimar el poder. Se crea una esfera pública en la que la mejor alternativa para salir de la pobreza es a través del narcotráfico o la vinculación a los grupos al margen de la ley.

En este sentido, se puede decir que el grupo de Teatro por la Paz buscar elevar la esfera pública mercantilista al ámbito de la resistencia y la participación — según lo que Habermas llamaría instancia crítica-. Pues sus discursos construidos colectivamente, hacen un llamado a promover espacios para la reflexión, una opinión pública de rechazo a los hechos marcados por el narcotráfico y el poder opresor de los grupos al margen de la ley, una opinión pública que sea consciente de que los valores tradicionales característicos de las comunidades del pacífico se han perdido producto de las dinámicas propias de la violencia y acceso a la vida fácil y la ley del menor esfuerzo.

En contraposición a este contexto de conflicto armado, los jóvenes y mujeres afirman que una de las formas de resistir cívicamente es a través de la recuperación simbólica del territorio.

El territorio, es el lugar donde habitamos, donde forjamos nuestra cultura o queremos transformar, queremos que las relaciones humanas sean como las de antes y creo que lo estamos logrando practicando valores como la fraternidad y la comunicación entre vecinos.

"Los barrios antes eran espacios de hermandad, ahora se convirtieron en espacios de miedo. [...] Queremos seguir llegando a los barrios para dignificar la vida, las relaciones humanas. Nuestros jóvenes nos han mostrado liderazgos en todos sus espacios de interacción, ayudando a transformar vidas y nuestras obras reflejan todo lo que nosotros queremos cambiar empezando por recuperar nuestro territorio"11.

El territorio es el espacio de encuentro, de comunicación y de permanente construcción y significación de las realidades. En la Antigua Grecia, por ejemplo, las polis era un espacio de reunión política entre los hombres y su territorio, en el que todos debían aportar para fomentar la felicidad y preservar a la comunidad. De acuerdo con Arendt (1993), en la articulación de las esferas públicas y privadas hay cosas que requieren ocultarse y que le son propias al ámbito familiar, laboral u otros espacios de interacción, también hay otras que necesitan exhibirse públicamente para que puedan existir.

Al tener presente este argumento y al relacionarlo con el grupo de Teatro por la Paz se logra apreciar que muchos aspectos de la esfera privada y que están relacionados con las dinámicas propias

11 Voces de los participantes en Taller de lluvia de ideas, 2015, realizado por el equipo de investigación, Tumaco. 
del conflicto armado que han vivido los agentes, son elevados a la vida de la esfera pública. Este espacio es una manera de reconstruir lo público desde el núcleo de la vida privada y todo esto es mediado a través de las prácticas comunicativas que les permite a los sujetos comprender, situarse en un contexto distinto, incluso reaprender de las experiencias que en otrora fueron victimizantes para elevar el estatus a ciudadano de hechos y de derechos.

En Tumaco hemos logrado trasformar la visión que tienen las organizaciones hacia las comunidades, que somos vulnerables, que necesitamos de ellos, que no podemos pensar por nuestros propios méritos, que no sabemos cuál es nuestro lugar. [...] Hemos construido otra forma de asumirnos como ciudadanos, hemos aprendido a ser conscientes que somos el cambio que nosotros somos quienes asumimos nuestra propia transformación. [...] Hemos logrado que las personas que hacemos parte de teatro tengamos una posición más crítica de los que nos sucede $^{12}$.

Lo anterior nos lleva a comprender desde las voces de los agentes del colectivo de Teatro por la Paz, que lo público trasciende del espacio vital común a todos, al papel activo de la ciudadanía. La reconstrucción de lo público para estas comunidades es crear una cultura del cuidado del otro, de dignificación de la vida humana, de transformación, de desnaturalización de la violencia, una forma de asumir el derecho a un territorio de paz. Un cambio de actitud de la sociedad permite cambios en las instituciones y en las organizaciones. La reconstrucción de lo público no es posible sin la apropiación de lo que Camps (1996) llama virtudes públicas como la solidaridad, la responsabilidad, la tolerancia y la profesionalidad, estas son herramientas ciudadanas para transformar la institucionalidad, los focos de dominación y la opinión pública manipulada.

Por su parte, Fraser (1993) plantea que el debate público es uno de los aspectos claves para gestar la paridad participativa. Es sólo a través de los debates que los agentes logran identificar los vacíos institucionales y emergen nuevas nociones de lo justo y se da lugar al reconocimiento. El debate público pasa por las acciones colectivas de ciudadanos que se piensan libres, con capacidad para la discusión y deliberación pública. Lo público, entonces, es inherente a la vida humana, lo público es la comprensión de una ciudadanía de alta intensidad para transformar el entorno para el bienestar colectivo. Reconstruir lo público para estas comunidades es recuperar la capacidad de indignación que la violencia les ha arrebatado y es promover de manera simbólica formas de recuperar la capacidad de comunicación en un contexto de miedo e incertidumbre.

El teatro no es sólo el lugar de encuentro con los jóvenes, es una forma de comprender mejor nuestra situación en todos los ámbitos de nuestra vida. Por ejemplo, en nuestro trabajo. Como profesora, mi deber es conocer mejor a cada uno de mis estudiantes no juzgarlos, porque ellos también viven en este contexto de violencia, es entender sus historias, y empezar a construir tolerancia, eso es reconstruir lo público, reconstruir las relaciones humanas y promover principios de respeto y tolerancia (Sonia Zapata, 2015. Entrevista individual, realizado por el Equipo de Investigación).

Finalmente, lo que se logra comprender es que el grupo de Teatro por la Paz ha logrado resignificar el papel del ciudadano en un contexto como el de Tumaco, pues, el orden común en estas sociedad históricamente maltratada es que la gente naturalice la opresión, quizás sea una herencia de la esclavitud, pero lo significativo es que aún existen iniciativas que pese a enfrentarse a un conflicto armado, deciden actuar, su motivación es la indignación, su permanencia se le atribuye al hecho de sentirse acompañados entre sí, su gestión política es la comunicación y su arma el discurso teatral, contenido de crítica y propuestas hacia la construcción de un territorio de paz.

12 Conclusiones, Taller de lluvia de ideas, 2015, realizado por el equipo de investigación, Tumaco. 


\section{Conclusiones}

Analizar las voces de resistencia del colectivo en función de lo público y la proyección política nos sitúa en diálogo con las ciencias sociales para comprender nuevos significados a conceptos clásicos como lo público y la resistencia. El trabajo de campo se convirtió es un insumo valioso para comprender cómo los sujetos le dan un nuevo significado a la política, la resistencia y el conflicto. Esto no hubiera sido posible sin las formas de comunicación ejercida por los actores, a través de ella se reconoce el valor de la lucha, se descubren nuevas formas sobrevivir juntos y se configuran nuevas formas de asumir el papel como ciudadanos.

Teatro por la Paz ha sido una experiencia interesante de abordar para comprender conceptos fundamentales como conflicto, lo público y la resistencia. Su organización, sus agentes y todas las subjetividades alrededor de la violencia, la cultura, la memoria y la reivindicación, han dado como resultado que los sujetos están construyendo alternativas distintas para entender los contextos de emergencia. El arte se convierte en un agente movilizador de prácticas de rechazo, de convivencia, de recuperación simbólica de un territorio y de transformación de vidas. Todo ello no es posible sin las formas en la que los agentes se comunican y se reconocen. Por eso, en un

\section{Referencias}

Alfaro, R. M. (1993). La comunicación como relación para el desarrollo. Perú: : Asociación de Comunicadores Sociales Calandria.

Arendt, H. (1993). La Condición Humana. Barcelona: Paidos.

Bobbio, N. (1985). Estado, gobierno y sociedad:por una teoría general de la política. México: Fondo de Cultura Económica.

Cadarso, LLorenzo Cadarso, P. (2011). Fundamentos Teóricos del Conflicto Social. Madrid: Siglo XXI.

Camps, V. (1996). El malestar de la vida pública. Barcelona: Grijalbo. momento de acuerdos entre las Farc y el Estado colombiano, se hace más que necesario comprender y visibilizar estás prácticas de emancipación que invita a la academia a seguir preguntándose por los procesos de desarrollo, convivencia y gestión de los consensos en sociedades donde el Estado no hace presencia ni se interesa por promover procesos de desarrollo humano y social.

Los integrantes de Teatro por la Paz asumen que la lucha es en doble vía, social y personal, que la resistencia no es sólo frente a los grupos al margen de la ley y el mismo Estado sino hacia un comportamiento de una sociedad que prefiere naturalizar la violencia y conformarse con lo que les toca. La resistencia a un conflicto armado supone construir procesos de memoria histórica, enseñar y promover a las nuevas generaciones los principios básicos de una sociedad como son la solidaridad, la honestidad y el respeto.

Vale la pena seguir indagando por este tipo de experiencias para pensar en una agenda de país que ahora está encaminado hacia un acuerdo de paz. Las comunidades nos han enseñado a través de estas experiencias que existen alternativas eficaces para promover la resistencia, la dignificación de la vida humana, la memoria histórica y la ciudadanía. Seguramente encontraremos más pistas que nos acerquen a formas de perdón, reconciliación e inclusión.

Chihu, A. (2006). El"Análisis de los marcos"en lasociología delos movimientos sociales". Iztapalapa: Universidad Autónoma Metropolitana Iztapalapa.

Dewey, J. (1966). Naturaleza Humana y Conducta. México: Fondo de Cultura económica., $2^{\mathrm{a}}$ edición.

Diocésis de Tumaco. (septiembre de 2014). Que nadie diga que no pasa nada. Tumaco, Colombia: Diocesis de Tumaco.

Echeverría, L. (octubre de 2012). Prácticas de Resistencia y construcción de ciudadanía en Tumaco: Estudio de caso del proyecto educativo 
Teatro por la Paz desde los marcos de acción colectiva. Bogotá, Colombia.

El País. (27 de octubre de 2013). Laura Hincapié. Obtenido de ¿Por qué las Farc se ensañaron con Tumaco? Recuperado de: http:// www.elpais.com.co/elpais/judicial/noticias/ pesar-volvio-luz-tumaco-sigue-tinieblas

El Tiempo. (2 de octubre de 2004). Enorme desfalco en Tumaco. El Tiempo, pág. 1.

El Tiempo. (26 de 06 de 2015). Mancha de crudo ya se extiende por $7 \mathrm{~km}$ de playa de Tumaco. Redacción Vida, pág. 1.

FIP,USAID y OIM. (2014). Dinamicas del conflicto armado en Tumaco y su impacapcto humanitario. Bogotá: Ideas para la PAz.

Foucault, M. (1994). Un diálogo sobre el poder y otras conversaciones. Madrid: Paidós.

Fraser, N. (1993). Repensar el ámbito público: una contribución a la democracia realmente existente. Debate feminista, 58.

Habermas, J. (1992). Historia y critica e la opinión pública: La transformación estructural de la vida pública. Barcelona: Gustavo Gili, S.A. .

Melucci, Alberto en Laraña E. (1994). ¿Qué hay de nuevo en los nuevos movimientos sociales? Madrid: Centro de Investigaciones (CIs).

Quintero, J. (4 de marzo de 2015). El Tiempo . En el Valle están siete de los diez municipios más violentos del pais. Recuperado de:, pág. 1. Obtenido de El Tiempo: http://www.eltiempo.com/colombia/cali/cifras-de-violenciasiete-municipios-mas-violentos-estan-en-elvalle/ 15337415

Ranciere, J. (2005). Sobre politicas estétcas. Barcelona: Universidad Autónoma de Barcelona.
Randle, M. (1998). Resistencia civil. Barcelona: Paidós.

Revista Semana. (17 de septiembre de 2014). Cuanto le cuesta la guerra a colombia. Revista Semana., pág. 1.

Rocha, C., Aldana, Y., y Rodríguez, L. (2013). La Radio Escolar para la Convivencia un modelo para armar. Bogotá: Coporación Universitaria Minuto de Dios.

Santos, B. (2012). De la Mano de Alicia . Lo social y lo politico en la posmodernidad. Bogotá: Siglo del Hombre Editores.

Silva García, G. (2008). Teoría del conflicto, un marco teórico necesario. Recuperado de http:// www.redalyc.org/pdf/876/87602203.pdf

Snow, D., \& Benford, R. (1992). Master frames and cycles protest. New Haven: Yale University.

Snow, D., Rochford, E., Worden, S., \& Benford R.(1986). Frame aligmet moviments, microbilizacion and movement participation. American Sociological Review 2., 464- - 481.

Teatro por la Paz. (2015). Teatro por la Paz- Tumaco. Montaje Teatral: "El olvido está lleno de memoria". Tumaco: Diocesis de Tumaco. Tumaco: Pastoral Social.

Useche, O. (2003). La potencia creativa de la resistencia a la guerra. 18. Bogotá.

Useche, O. (2012). Diferencia, subjetivdades en resistencia y micropolítica del acontecimiento. En C. Piedrahita, D. Álvaro y , \& V. Pablo, Subjetividades Politicas: Desafíos y debates latinoamericanos. Bogotá: Universidad Distrital Francisco José de Caldas. 